\title{
Hydraulic Modelling and Mapping of the Risk of Flooding in the City of Meknes by (Hec - Georas)
}

\author{
Rhazi Abdelaziz*, Essahlaoui Ali, Elouali Abdelhadi, El Hmaidi Abdellah \\ Department of Geology, Faculty of Sciences, University of Moulay Ismail, City of Meknes, Morocco
}

Email address:

azirhazi@gmail.com (A. Rhazi), Essahlaoui@gmail.com (A. Essahlaoui)

${ }^{*}$ Corresponding author

To cite this article:

Rhazi Abdelaziz, Essahlaoui Ali, Elouali Abdelhadi, El Hmaidi Abdellah. Hydraulic Modelling and Mapping of the Risk of Flooding in the City of Meknes by (Hec - Georas). Hydrology. Vol. 6, No. 1, 2018, pp. 10-17. doi: 10.11648/j.hyd.20180601.12

Received: December 4, 2017; Accepted: December 26, 2017; Published: January 16, 2018

\begin{abstract}
The urban areas are the most vulnerable to flooding especially those located on sites exposed to these risks including the city of Meknes. The objective of this work is to highlight the urban environment through this case study. To do this, it has adopted an approach map and hydraulic modeling involving to the Compendium and the crossing of map data as well as to the different data collected through the tools to serve the development of the territories while developing a map of danger relating to the risk of flooding in the city of Meknes.
\end{abstract}

Keywords: GIS, Maps, Flood Risk Management, Prevention

\section{Introduction}

To the like other Mediterranean countries Morocco, by its semi-arid climate, has not escaped the effects of the floods which are directly linked to climate change.

A retrospective of the past shows that over time, there was the estates alternating and extremes of climate which manifest themselves in long periods of droughts and short periods of flooding. The periods of drought were long and frequent and follow one another and are alternating sometimes by wet and rainy at the point of floods (B. Damnati, 2006) [1].

In effect, it is found of floods that have marked our history and which have engraved our memory. There is place to evoke the flood that devastated the city of Sefrou dated 25 September 1950, when the city was flooded with a blade of water of $6 \mathrm{~m}$ high, causing hundreds of deaths. Also the one that has ravaged the Ziz valley on 05 November 1965, leaving 25000 inhabitants homeless and who has imposed the construction of the dam Hassan Adakhil upstream, in the north of the city of Errachidia; or again that of the Moulouya occurred on 23 May 1968 and which was of a violence that she took the seat on the left bank of the dam Mohammed V (the flood had a peak flow of $7200 \mathrm{~m}^{3} / \mathrm{s}$ and a volume of 570 million $\mathrm{m}^{3}$ either the capacity of the retainer.
Without losing sight of the catastrophic events that have struck the Ourika strongly in 1995, El Hajeb in 1997, Settat and Mohammedia in 2002, Tan Tan, Nador, Al Hoceima and Khénifra in 2003. Also the violent floods of the Sebou that cross the Gharb and which constitute a permanent danger on the groupings of housing, cities and riparian centers in overflowing its bed in average every two years (Belksiri, Sidi Slimane, Meknes etc.). Also, during the years excessively rainy, as in the case of years $(2008,2009,2010)$, the plain of Gharb (Sidi Slimane, Sidi Yahya, Sidi Kacem, etc.) has undergoes floods and flooding, the year 2016 has us floods especially in a few Coastal Cities. As in the case of the cities of Salé, Rabat, Tangier, Khénifra, Tinghir, Ourika etc. The consequences were adverse on all plans, economic and social. This article comes to put the emphasis on a city such as Meknes, who knows a urban sprawl, in every sense, without as much to take those risks in the considerations by the documents of town planning which are the plans for urban development and the diagrams directors of urban development which are generally by real estate opportunities Diagnostic report (SDAU, 2013) [2].

\section{Presentation of the Study Area}

The study area (Figure 1) is located in the western Saïs (plateau of Meknes). It is limited by the valley of the wadi 
Beht and the Central Plateau to the West, the plain of Fez with is the mountains of the pre-Rif in the north, and the mountains of medium-Atlas Mountains to the south. The region is notched by the collection of several valleys and valleys according to an axis south-west, north-east (Rghani, 1992) [3].

The city of Meknes, the main city of this plateau, is compartmentalized into several parts of plateau more at least extended, separated from each other by valleys with depths important, whose width varies from the upstream downstream and from one valley to another.

The main oueds who cross the city are: the oued Boufekrane, the wadi Ouislane and the Oued Bou Ishak. The agglomeration of Meknes is composed of three commons essential to know: Meknès, Toulal and Ouisslane. It is located on the plateau of Saiss-Meknès.

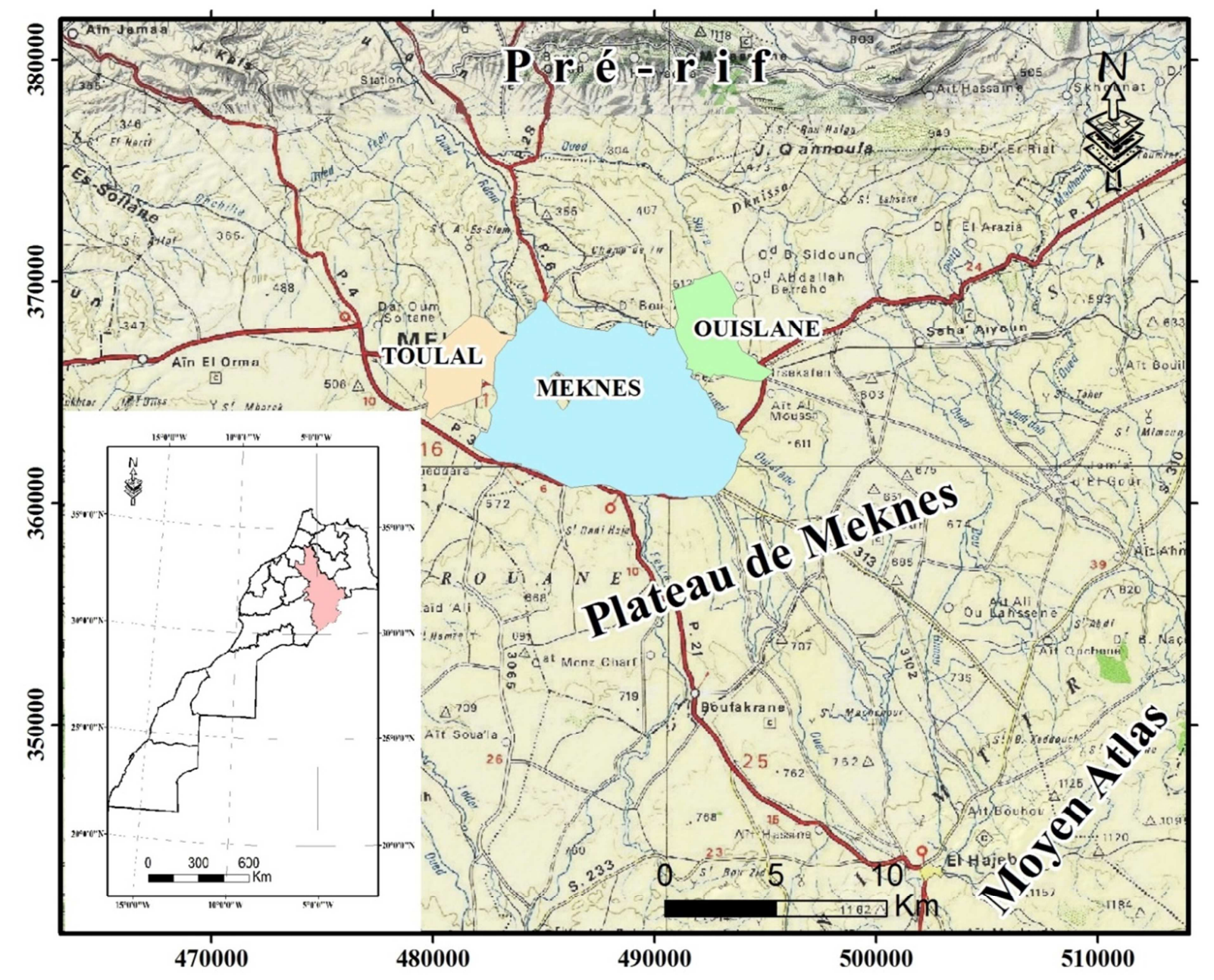

Figure 1. Geographical situation of the city of Meknes.

\section{Materials and Methods}

The basis of cartographic data used in the framework of our study is constituted by: the topographic map of the region of Meknes to the $1 / 25000$ scales, the map in urban areas in $1 / 10000$, the SDAU at 1:5000 the development of the plan in the $1 / 2000$ (AUMK, 2008) [4] several software's have been used:

a) Software ArcGIS: it is a software that presents the particularity certainly manage data geo referenced, but its performance is based mainly on the quality of its integration in an organization, the implementation of methods to gather, analysis, process, Share and share geographic information

b) HEC-RAS is software modelling dimensional which has been developed by the US Army Corps of Engineers. HEC-RAS means "Hydrologic Engineering Center - River Analysis System". It allows among other things to do simulations in permanent regimes and transitional measure of a river.

c) HEC-GEORAS is a coupling of HEC-RAS, and ArcGis: This coupling facilitates the entry of the data for the modelling in HEC - RAS

\section{Results and Discussion}

a) Digital model of the terrain

From the digital terrain model (DTM) (Figure 2) from the watershed of the Oued Boufekrane, we proceeded to the calculation of the morphometric characteristics (Table 1) (maximum height and minimum, average slope, the most 
long course of water, etc.), and also the representation in $2 \mathrm{D}$ or 3D of the topographic surface. Several thematic maps have been extracted from this DEM, which we quote: The map of slopes, map of orientations, hypsométrique card.

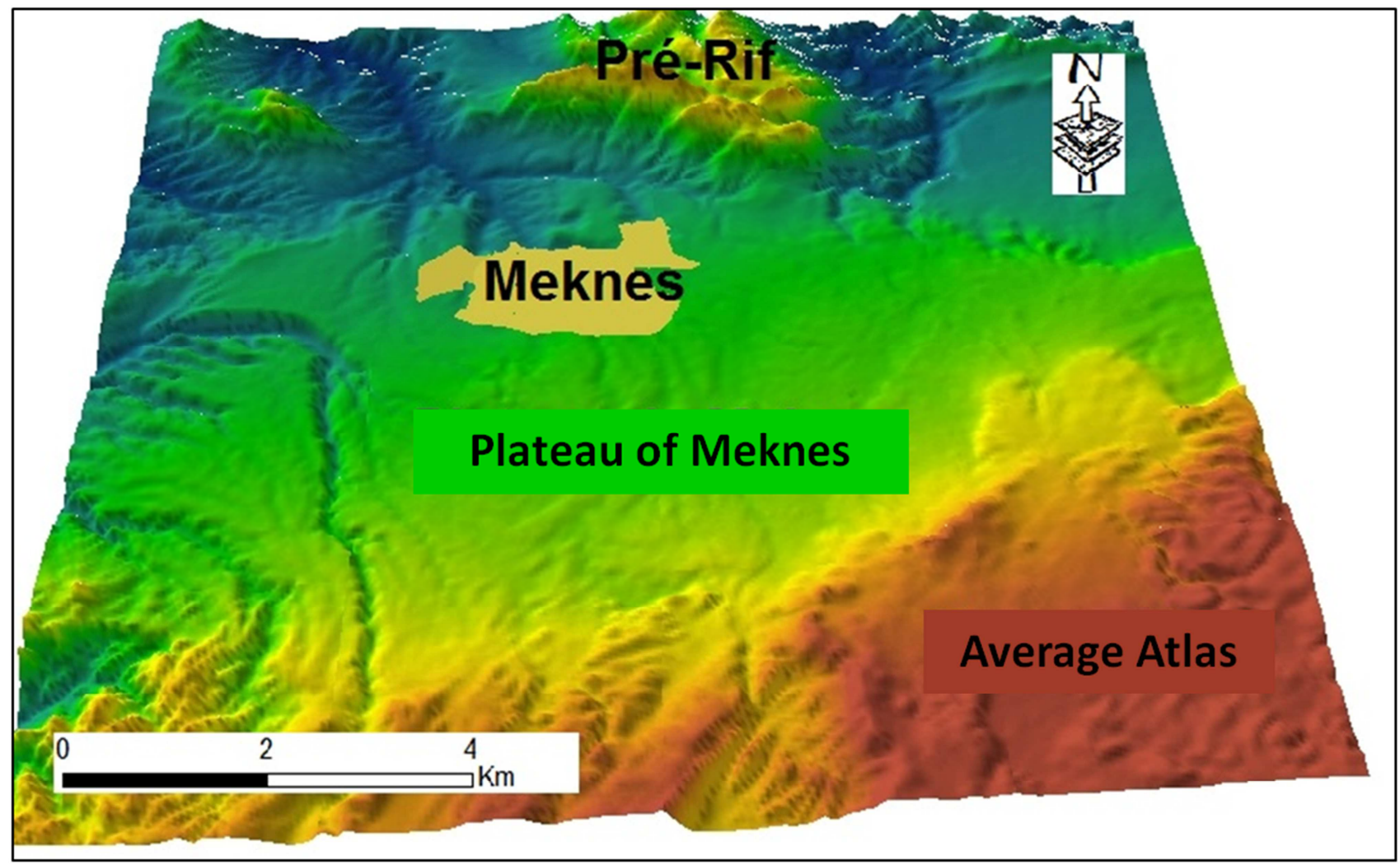

Figure 2. Digital Terrain Model of the watershed of the Oued Boufekrane.

b) Time of concentration

The time of concentration of water on a BV is defined as the time taken by a drop of water falling on the farthest point (hierologically) of the outfall to achieve them (Ourahhou, M., 2009) [5]. This value is influenced by various morphological characteristics (Table 1), and which are: The size (the surface); the form (surface and length) and the relief of the basin (length and slope). To these factors will add still further the type of soil, the vegetation cover and the hydrological characteristics of the hydro graphic network.

Table 1. Morphological characteristics of the watershed of the Oued.

\begin{tabular}{lllll}
\hline \multirow{2}{*}{ Bassin versant } & Surface & Longueur & Pente & Dénivelée \\
\cline { 2 - 5 } & $\mathbf{K m}^{2}$ & $\mathbf{( K m})$ & $\mathbf{( \% )}$ & $\mathbf{( m )}$ \\
\hline Oued Boufekrane & 383.94 & 52.10 & 1.5 & 804 \\
\hline
\end{tabular}

To do this we have adopted some empirical formulas, namely: (Table 2 and 3)

The value is the average of those obtained by the methods of Ventura, Kirpich and Passini.

Table 2. Time of concentration (TC) from empirical formulae.

\begin{tabular}{lll}
\hline & Giondotti & Ventura \\
\hline Formules de Tc & $\frac{\left(4 . S^{0.5}+1,5 L\right)}{0,8\left(h_{\text {moy }}-h_{\min }\right)^{0,5}}$ & $7,62\left(\frac{S}{P}\right)^{0,5}$ \\
$\mathrm{Tc}(\mathrm{mn})$ & 15.005 & 122.73 \\
\hline
\end{tabular}

Table 3. Time of concentration (TC) from empirical formulae.

\begin{tabular}{lll}
\hline & Kirpich & Passini \\
\hline Formules de Tc & $\frac{1}{52}\left(\frac{L}{\sqrt{I}}\right)^{0,77}$ & $\frac{6,48^{*}(L S)^{1 / 3}}{P^{0,5}}$ \\
$\mathrm{Tc}(\mathrm{mn})$ & 90.18 & 60.01 \\
\hline
\end{tabular}

c) Flow Calculation centennial using the rational method to an area of the means and of the major basins:

$$
Q_{p}(T)=0,278 * C_{r}(T) * I\left(t_{c}, T\right) * S
$$

ITC: average intensity of rain (in $\mathrm{mm} / \mathrm{h}$ ) during the time of concentration Tc.

$\mathrm{S}$ : surface in $\mathrm{Km}^{2}$

$\mathrm{CR}$ : coefficient of runoff (Clay $=0.60)$

The calculation of $\mathrm{i}(\mathrm{TC}, \mathrm{T})$ is done according to the formula of Montana

$$
I(t, t)=a(T) / t b(t)
$$

With $\mathrm{a}$ and $\mathrm{b}$ are the coefficients of dependent on the frequency of the rain,

$\mathrm{T}$ : period of return and $\mathrm{t}$ : Duration of rain in $\mathrm{mm}$.

$$
\text { I }(24 \mathrm{~h}, 100)=11.25 \times 53.1-0.69=0.73 \mathrm{~mm} / \mathrm{h}
$$

In applying the formula of the rational method, one obtains: 
$\mathrm{Q} 100=0.6 \times 0.73 \times 383.94 / 3.6=46.71 \mathrm{~m}^{3} / \mathrm{s}$

\section{Determination of Areas Vulnerable to the Risk of Flooding}

Taking account of the morphological characteristics of the BV drawn from a detailed tin of the studied region; from the knowledge of the hydrological behaviour of the wadi, we have been able to define the major bed, the minor bed along the two wadis of Boufekrane and its tributary the Oued Bou Ishak. By the result of the cross-section in sufficient number to define the actual topography of the two wadis and also limit in space the beds minors and major beds. The result obtained is transported to the Software HEC-RAS (Figure3 and 4).

\begin{tabular}{|l|}
\hline 1 Project \\
\hline 2 Géomètre \\
\hline 3 Flaw \\
\hline 4 Plan \\
\hline 5 Géométrie \\
\hline 6 Simulation \\
\hline 7 Résulte \\
\hline
\end{tabular}

Figure 3. Organization Chart HEC-RAS (milestones).

This last requires knowledge of the conditions to the limits of the wadis, the knowledge of the factors of Manning (Nvalue) (value dependent on the occupation of the soil in the vicinity of the Oued. Taking into account the values obtained during the hydrological studies (rates of return maximums Q10, Q50 and Q100, etc.) (ABHS, 2013) [6], we have been able to establish areas flooded according the hypothesis chosen.

The flooded areas for each return flow is mapped and subsequently superimposed on urban plan (AUMK, 2010) [7], available to the city of Meknes; this has been able to define in reality urban areas affected by this hazard. (Figure 5) illustrates well the spatial distribution of these areas as well as the urban subdivisions which present a great risk.

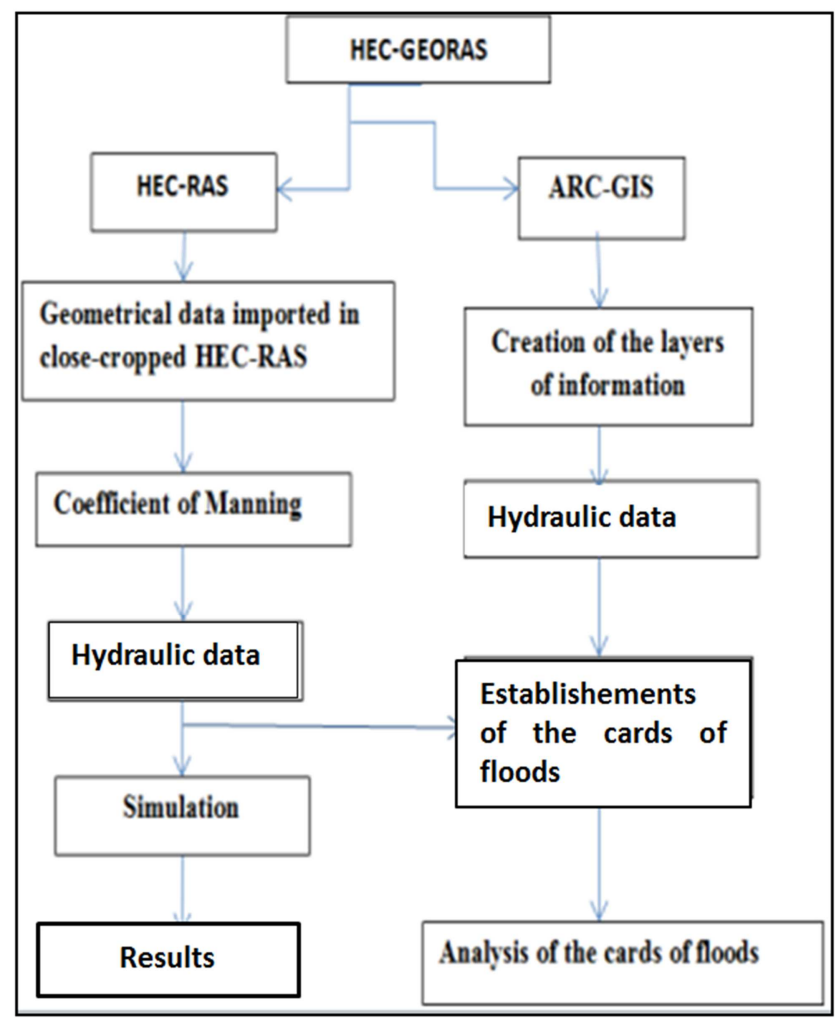

Figure 4. Organization Chart (operation of HEC-GEORAS).
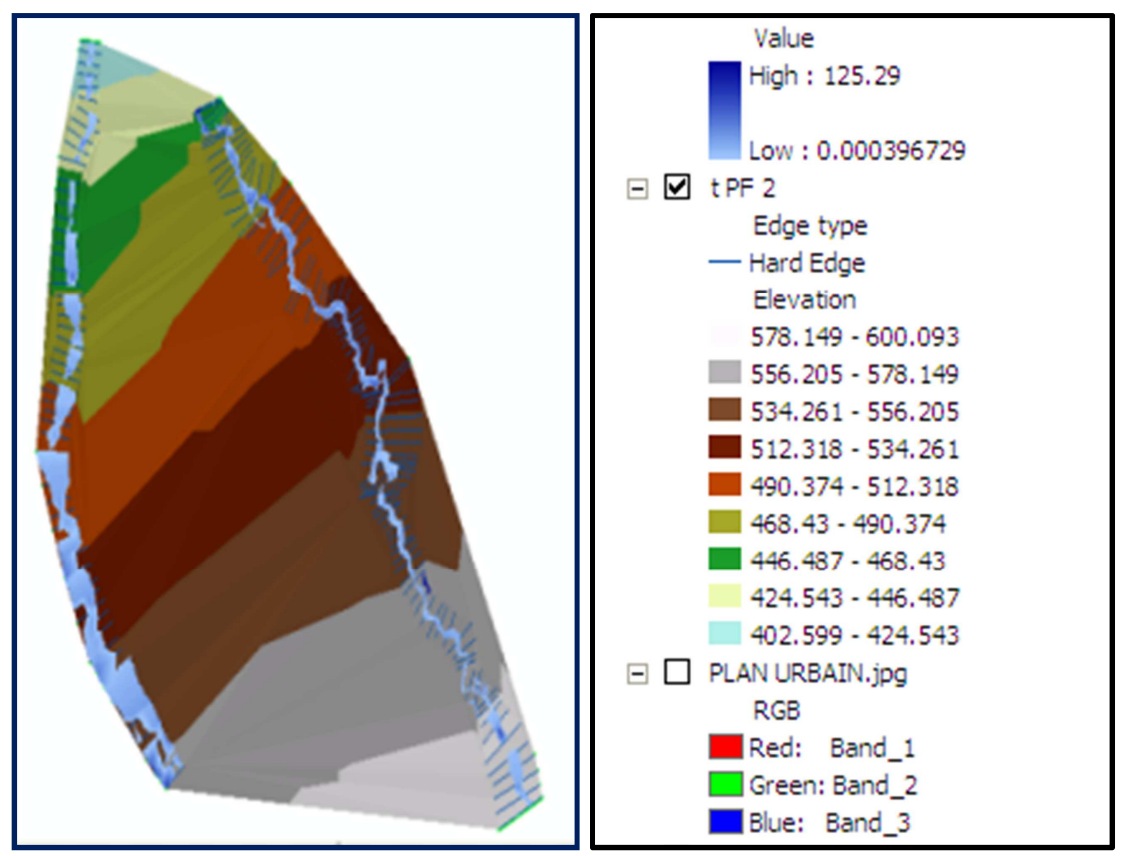

Figure 5. Areas of floods obtained after hydraulic modelling and overlay on the TIN. 


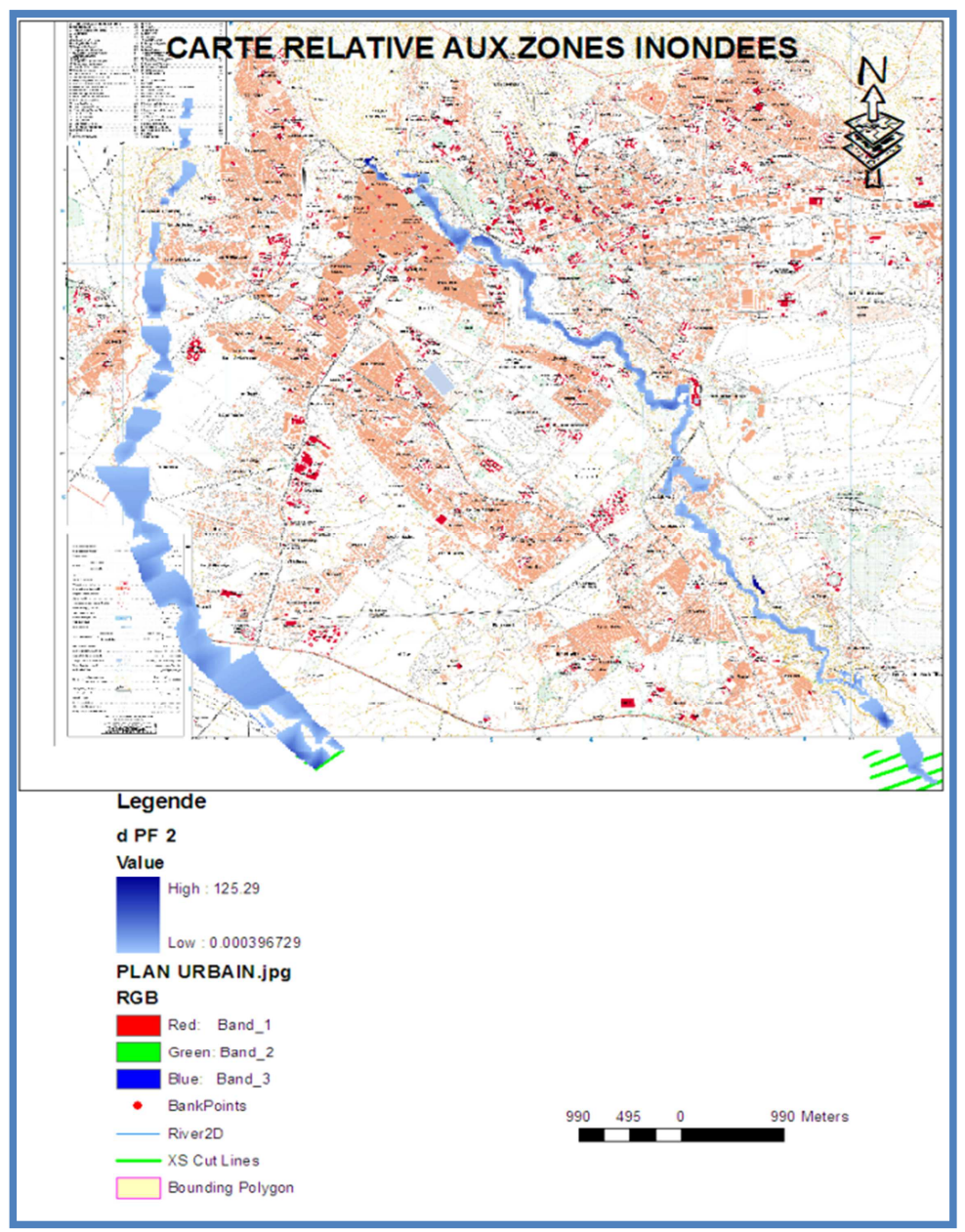

Figure 6. Areas Flooded superimposed on urban plan of the city of Meknes.

The flooded areas for each return flow is mapped and subsequently superimposed on urban plan available to the city of Meknes; this has been able to define in reality urban areas affected by this hazard. (Figure 6), illustrates well the spatial distribution of these areas as well as the urban subdivisions which present a great risk.

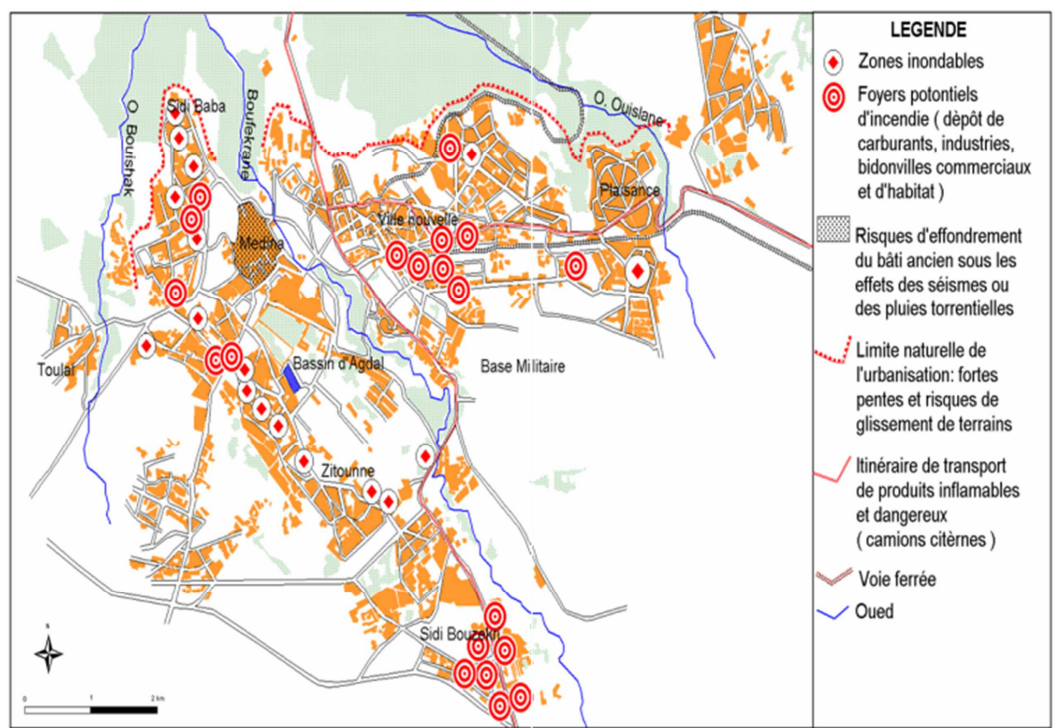

Figure 7. Map of areas at risk (Agenda21, 2004).

The map relating to the vulnerable areas generated simultaneously by GIS and Hec-GéoRas, the card of the risks referred to in Environmental Profile (Agenda 21) [8], (Figure 7) and validation on the ground are not sufficient to map 
actually the areas at risk. To do this, and given its interest, it has adopted the approach map of risk which is based on two criteria which are the probability and the intensity.

\section{Map of Relative Vulnerability to Risks of Flooding in the City of Meknes}

The development of map of vulnerability is mainly based on the modelling tools such as (HEC-GéoRAS) and of the surveys on the scene interogeant the population that lives in sites exposed to the risks of flooding.

Also the nature of network of assinissement liquid which has in its majority of a unitary system, which collects both the wastewater and the waters pluvieles. Without losing sight of the nature of the topographic of field and the button of urban space in general, notament tracks of development Structuring and trotoires. They promote the speed of ruisselements of waters to glances not maintained. This has allows you to classify the events of Low Frequency, Medium and High.

Sites located downstream and in channels containing not floor drains to grids and this approach is to generate the map and this, in combinisant appropriate tools and by the Geographic Information System (Arc Map). As well, it has been able to generate a map of resulting synthesis of based on a crossing of the different data. This is a card that will be classified in fore danger areas: red, orange and yellow and yellow white as presented in the following table (Figure 8).

\section{Factors Favoring the Risk of Flooding Urban Areas}

What that one is located in front of the impossibility to give a precise definition to the risks anthropogenic. These risks are often unique to the phenomenon of urban concentration: neighbourhoods' not sensitive regulatory generators of the major groupings, buildings at several levels,

Homes economic or other. However, these risks affect sites with strong concentration of constructions, industries and populations. "Urbanization, sometimes old, of certain areas at risk, as is the case of neighbourhoods of the former mellah and Berrima, exposes, in case of heavy rainfall, floods (Agenda 21, 2004) [8].

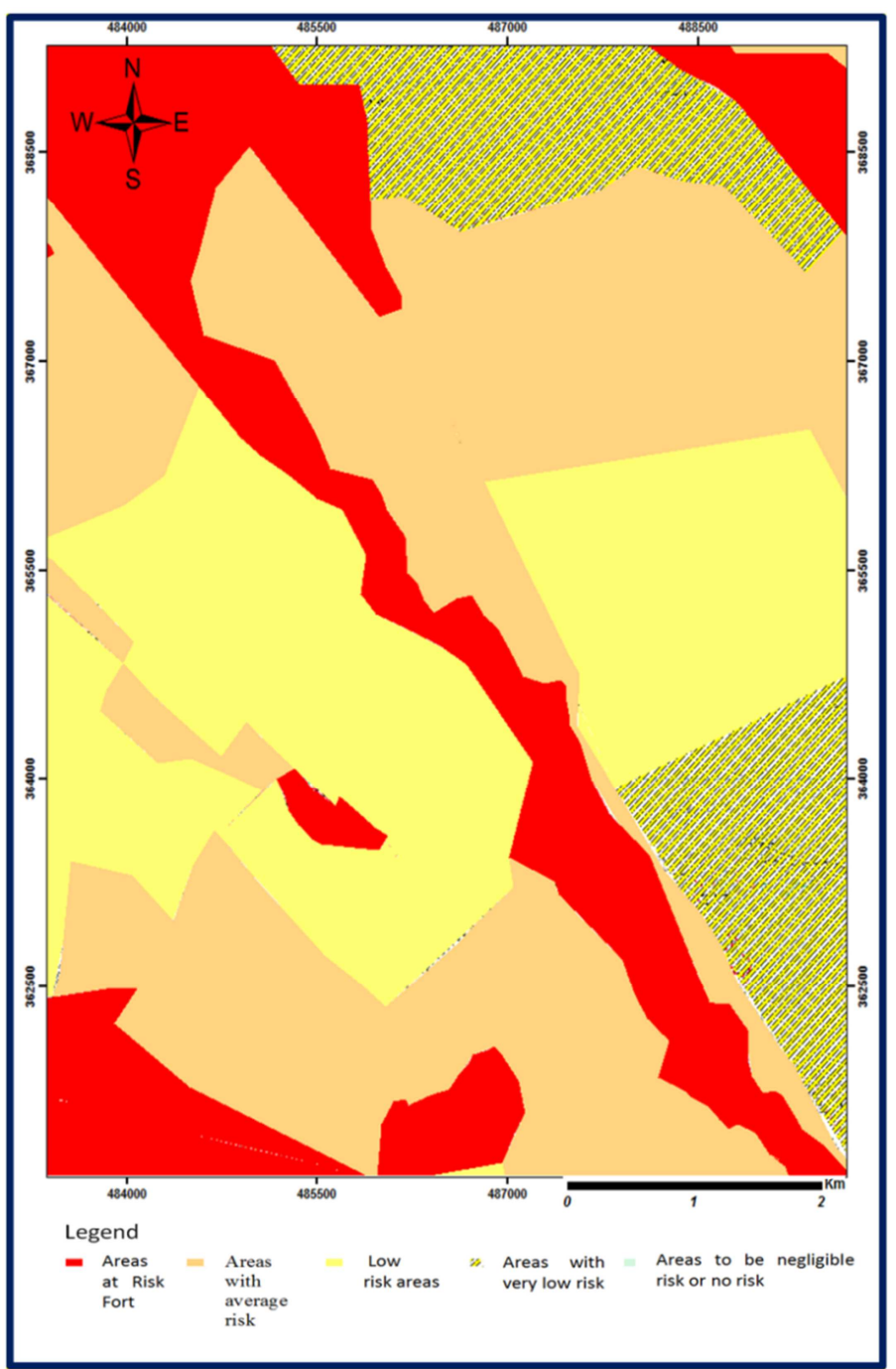

Figure 8. Map of the classification of areas at risk of flooding. 
The lands affected by this typology of risk, are generally non- and who open to the urbanization are hit by easements Construction prohibited according to the regulatory provisions of the documents of town planning, and this by their fact that they are either unfit to urbanization for Geotechnical considerations, hydrological, geological or topographic often; either that they are considered simply of protection zones (natural heritage, historic heritage). It must be said that these lands not open to the urbanization correspond to the alluvial background of the 3 Valleys passing through the city of Meknes and their flanks composed of marls which may be affected by the deformations, landslides and swelling.

Has noted that these areas not Open to the urbanization are characterized by steep slopes exceeding $20 \%$ and that limit urbanization in the north of the city. The nature of field rugged coincides with limestone outcrops degraded and unstable, where the risk of landslides and landslides.

"The whole of these lands not Urban planning occupies an area of 1300 ha, or $43 \%$ of the areas that were non-urbanized areas within the urban perimeter in 1992". (Agenda 21, 2004) [8] This category also affects the non-constructible areas (non aédificandi) of rights-of-way for the protection of the ramparts and historical monuments and heritage in the broader sense.

Note that the majority of the lands that constitute these spaces to multiple risks, have nevertheless been invaded by the spontaneous urbanization or even lawful (authorized), as is the case of a few subdivisions are located in the vicinity of the ramparts or on the slopes of valleys and in the careers (sabouni career and career said Haj Driss south of Meknes.

According to what we have just presented, we can say that the notion of vulnerability to natural hazards in urban areas is based on four essential factors. Two external factors is summarizing in:

- Acceleration of urban growth;

- The imbalance of the factors of socio-economic development and the choice of policies in the development of the territory: excessive concentration of cities, urban canters, industrial neighbourhoods, industrial poles, networks or urban relay incomplete, insufficient policy Housing and relocation, etc.

The 2 other factors of vulnerabilities of the urban environment, are regarded as intrinsic:

a) There are first of all the destructive effects of natural phenomena, which are aggravated by the very structure of materials and the urban morphology. This last accentuates the induced effects, since the early site of cities was quickly overwhelmed by the consumption of the available space, toward sites exposed or dangerous.

b) The second factor is the segmentation accentuated of urban society, which reflects the poor development and conflict socio-economic conditions in a limited space and coveted annuity (soil, mastery of the land, financial and political interests).

Certainly, the city of Meknes is vulnerable because of high concentration of populations in sites exposed to different risks natural, technological and social. But this situation is aggravated by two facts to know (Diagnostic Report, 2013) [9].

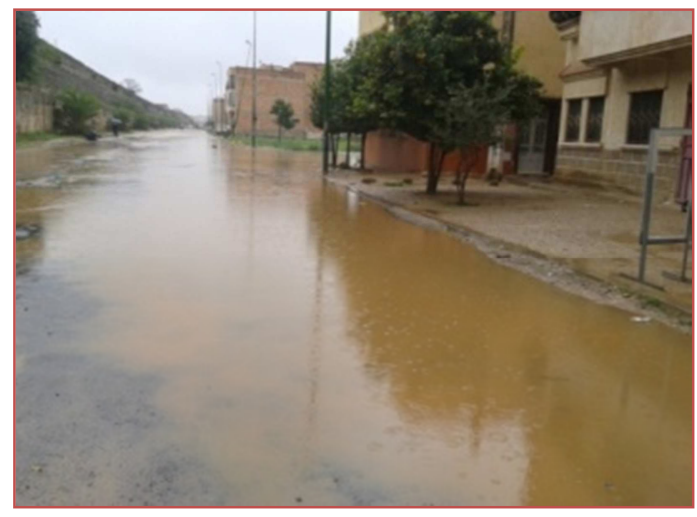

Figure 9. Illustrate a few cases of flooding.

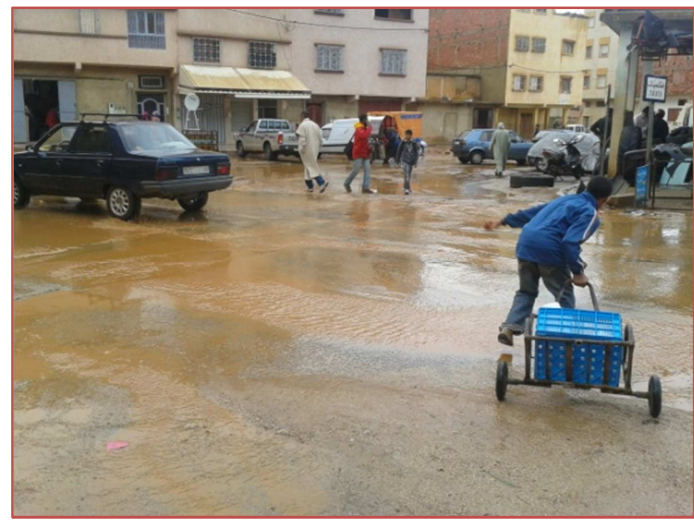

Figure 10. Illustrate a few cases of flooding.

Meknes is an environment by anthropogenic the urban extension toward areas with some dangers (slopes, Major beds, ravines...), this increases disproportionately of effects induced by the phenomena generators of damage (in urban areas due to the failure of the sewerage network especially in areas that are liable to flood of origin).

Also, Meknes has a morphology exacerbating the vulnerability of sites such as: the valleys, careers, in assessing spectacularly of initial Spaces a little dangerous to hazardous spaces strictly non-constructible.

The association of these two facts certainly led to the construction of a strong correlation linking urban morphology, which imposed geographically by the initial site (valleys, slopes) or not controlled on spaces unbuildable slopes and an exhibition quasi-permanent to the risks threatening.

\section{Conclusion}

During all phases of our research, it has not ceased to look for the information on the floods to adopt the historical approach to better study the recurrence of this risk but in vain. It has not adopted the geomorphological approach 
because of the embankments and the constructions camouflaging the traces of debris that constitute some kind of good indicators of the limits reflecting the excesses of the wadis.

The tools of globalizations we have given good results while identifying areas at risk, that was validated in the reality in the course of these years devoted to this modest research.

Through these tools, it was able to map the risk of flooding, and as results was found in large open areas to urbanization and which are under permanent threat, with regard to many of the area of Marjane and the urban pole of Ait Ouallal.

Also the proliferation of habitat non regulatory on vulnerable sites and devoid of any basic infrastructure, including the network of sanitation.

The city of Meknes is an environment by anthropogenic the urban extension toward areas with some dangers (Slopes hays, Major beds, ravines...), this increases disproportionately of effects induced by the phenomena generators of damage (urban areas due to the failure of the sewerage network especially in areas that are liable to flood of origin). This state of the urban fact has been exacerbated in some communities including the new town by the conversion of habitat family Mono (villas) to a zoning of building up by times 10 floors and sheltering several households while the sanitation system is unitary and remains under dimensioned to debits received.

Then, Meknes has a morphology exacerbating the vulnerability of sites such as: the valleys, the careers. In assessing spectacularly of initial Spaces a little dangerous to hazardous spaces strictly non-constructible.

The association of these two facts certainly led to the construction of a strong correlation linking urban morphology, which imposed geographically by the initial site (valleys, slopes) or not controlled on spaces unbuildable slopes and an exhibition quasi-permanent to the risks threatening.

\section{References}

[1] (B. Damnati, 2006). Climatic variations in the past, present and future: an overview of global and regional (Africa and Morocco), 189.

[2] (SDAU, 2013) Forward report, 2013 in the matter of the establishment of steering schematic 'urban development (SDAU), Urban Agency of Meknes.

[3] (El Idrissi - Rarhani M., 1992), Differentiation of the soils of the plateau of Meknes. "Relationships with the model and the calcareous substrate", Doctoral thesis, University of Pierre and Marie, Paris.

[4] (AUMK, 2008), Urban Plan of the agglomeration of Meknes, Urban Agency of Meknes.

[5] (Ourahhou, M., 2009), Ourahhou M., 2009. Hydrological study of watersheds. Regional Office of agricultural development of Tafilalt, Service rural equipment.

[6] (ABHS, 2013), (agency of the Hydraulic Basin of Sébou), 2013. Atlas of the flood prone areas in the basin of Sebou, Region Meknès-Tafilalt, January 2009, prepared by the Agency.

[7] (AUMK, 2010), Urban Plan of the agglomeration of Meknes, Urban Agency of Meknes.

[8] (Agenda, 2004), Environmental profile of the city of Meknes, 2004.

[9] (Diagnostic Report, 2013) Diagnostic Report, 2010 and developed by the Urban Agency of Meknes. 